\title{
Principios de organización administrativa en la estructura institucional del MERCOSUR
}

\author{
NATASHa Suñé ${ }^{1}$
}

\section{RESUMEN}

A partir de 1994, con la suscripción del Protocolo de Ouro Preto (POP), que otorga al MERCOSUR personalidad jurídica internacional y lo dota de una estructura institucional, surgió el interrogante de si los principios de organización del derecho administrativo serían aplicables a estos nuevos órganos regionales. Nos focalizaremos en entender los principios de organización administrativa que rigen en la estructura institucional del MERCOSUR, basando el análisis en los principios de organización administrativa del derecho administrativo. Veremos cómo esta estructura ha creado sus propios principios ya que no podrían trasladarse de modo supletorio principios y normas de ordenamientos jurídicos ajenos a la estructura regional.

Palabras clave: principios, organización, estructura, MERCOSUR, derecho administrativo.

1 Abogada por la Universidad Nacional de La Plata (UNLP), Buenos Aires, Argentina. Maestranda en Derecho Administrativo y Administración Pública en la Universidad de Buenos Aires (UBA), Buenos Aires, Argentina. Encargada del Área Jurídica del Tribunal Permanente de Revisión del MERCOSUR.CCorreo-e: natasha_s1983@hotmail.com Fecha de recepción: 8 de diciembre de 2014. Fecha de modificación: 20 de febrero de 2015. Fecha de aceptación: 3 de abril de 2015. Para citar el artículo: Suñé, N. (2015). Principios de organización administrativa en la estructura institucional del MERCOSUR. Revista Digital de Derecho Administrativo n. ${ }^{\circ}$ 13, Universidad Externado de Colombia, pp. 211-233. DOI: 10.18601/21452946.n13.11 


\section{Organizational Administrative Principles in MERCOSUR's Institutional Structure}

\section{ABSTRACT}

Since 1994, with the signing of the Protocol of Ouro Preto (POP), which granted MERCOSUR with international legal personhood and provided it with an institutional structure, the question of whether organizational principles of administrative law would apply to these new regional bodies has emerged. This paper focuses on understanding the principles of administrative organization governing the institutional structure of MERCOSUR and bases its analysis on the organizational principles of administrative law. It considers how this structure has created its own principles since they were not able to supersede norms and principles established in foreign regional legal frameworks.

Keywords: Principles, Organization, Structure, MERCOSUR, Administrative Law.

\section{INTRODUCCIÓN}

Hace 20 años se suscribía entre los cuatro Estados originarios, Argentina, Brasil, Paraguay y Uruguay, el tratado fundacional del Mercado Común del Sur (MERCOSUR), Tratado de Asunción ${ }^{2}$, cuyo objetivo, establecido en el artículo primero, consiste en la creación de un mercado común. Con posterioridad, en 1994, se suscribió el Protocolo de Ouro Preto (POP), que otorga al MERCOSUR personalidad jurídica internacional y lo dota de una estructura institucional con miras a la concreción del bloque económico. Desde el momento de la creación de instancias intergubernamentales entre los Estados que componen el MERCOSUR ha surgido el interrogante jurídico de si los principios de organización del derecho administrativo serían aplicables a estos nuevos órganos regionales. Más aun cuando en los Estados integrantes priman principios de organización administrativa.

En la presente investigación se analizan la estructura institucional del MERCOsur, las características de los órganos que componen la misma, y su clasi-

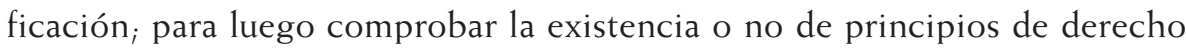
administrativo aplicables a la organización administrativa de esa institución

2 El 26 de marzo de 1991 entre los Presidentes de ese entonces, Carlos Saúl MenEm (Argentina), Fernando Collor de Mello (Brasil), Andrés Rodríguez (Paraguay) y Luis Alberto Lacalle Herrera (Uruguay), y sus respectivos Cancilleres. Posteriormente, y ya en una nueva etapa histórica del MERCOSUR, se incorporó como nuevo miembro pleno Venezuela, el 12 de agosto de 2012, y se encuentra en proceso de adhesión Bolivia. 
supranacional. Todo esto, con el fin de esbozar los principios de organización administrativa que rigen en la estructura institucional del MERCOSUR.

En ese sentido el método que emplearemos es el inductivo, puesto que partiendo del análisis de los componentes orgánicos y funcionales de las instituciones del MERCOSUR se identificará si los principios que rigen las administraciones públicas nacionales son replicables al MERCOSUR como estructura administrativa supranacional. Esto nos permitirá responder al interrogante jurídico de cuáles son los principios que deben orientar o estar presentes en la organización de este sistema supranacional.

\section{ESTRUCTURA INSTITUCIONAL DEL MERCOSUR}

Para comenzar definiremos a la organización administrativa como la "estructura técnico jurídica" destinada al correcto funcionamiento de una organización mediante la construcción de una estructura de órganos y la respectiva atribución de competencias. En ese orden de ideas podemos observar que los procesos de integración regional, sin importar la profundidad de su integración, desarrollan estructuras de órganos para realizar los cometidos propios del proceso de integración. Así,

"los procesos de integración constituyen fenómenos originales, multidimensionales y complejos que - por la índole de sus objetivos y metas- se organizan institucionalmente intentando de este modo dar a dicho proceso de integración un marco jurídico que les brinde seguridad, continuidad, permanencia y asegure la consecución de los objetivos y compromisos asumidos por el conjunto de Estados que suscriben un acuerdo de integración" (GAJATE, 2014).

Por ende, la estructura técnico-jurídica que se edifica en un proceso de integración determinado se relaciona claramente con las necesidades del proceso y los objetivos fijados en los tratados y las normas de creación. Como mencionamos, la estructura institucional del MERCOSUR nació con la suscripción del Tratado de Asunción, y se perfeccionó con el el Protocolo de Ouro Preto, que otorgó al MERCOSUR personalidad jurídica internacional y una estructura institucional tendiente a cumplir los cometidos enunciados en los tratados ${ }^{3}$.

En concordancia con GIANNINI, tradicionalmente se considera que son dos las condiciones necesarias para la aplicación de principios de organización administrativa: la existencia de una estructura institucional y la asignación de funciones propias (GIANNINI, 1991). En ese sentido, es posible afirmar que las

3 Así veremos cómo la estructura institucional del MERCOSUR va mutando a lo largo de los años en razón de las nuevas dimensiones que incorpora a partir del año 2003 (derechos humanos, políticas sociales, participación ciudadana, etc.). 
condiciones están dadas en el MERCOSUR para la aplicación de principios de organización administrativa. Veremos entonces si esos principios aplicables son los del derecho administrativo o si los principios que rigen la estructura institucional del MERCOSUR presentan algunas particularidades.

\section{1. Órganos DEL MERCOSUR. MODELO ESTRUCTURAL}

Para comprender qué tipo de principios de organización administrativa serían apropiados para la estructura institucional regional habrá que analizar en un inicio las características propias de los órganos del MERCOSUR.

Para una aproximación a este tema debemos diferenciar las estructuras organizacionales de las técnicas de distribución de funciones o competencias. El modelo estructural, compuesto por órganos y entes, está íntimamente vinculado con el de distribución de competencias descentralizadas (entes) y desconcentradas (órganos). El motivo de la vinculación consiste en que los órganos no tienen personalidad jurídica propia (SANTAMARÍA PASTOR, 1984) ${ }^{4}$, a diferencia de los entes que gozan personalidad jurídica y pueden adquirir derechos y contraer obligaciones (BALBIN, 2008). Mientras los órganos son parte de lo que en derecho administrativo se denomina modelo de administración centralizada ${ }^{5}$, el modelo de administración descentralizado está integrado por entes ${ }^{6}$.

En el derecho del MERCOSUR solo tiene personalidad jurídica la organización regional en sí, ejercida dicha titularidad por el Consejo de Mercado Común $(\mathrm{CMC})^{7}$, salvo expreso mandato al Alto Representante del MERCOSUR. Mientras

4 No gozan de personalidad jurídica propia porque consisten en unidades funcionales internas a una estructura mayor que goza de personalidad jurídica. "Órgano administrativo es un concepto aplicable a todas las unidades funcionales creadas por el Derecho en que se estructuran internamente las entidades públicas (unidades no personificadas, como después veremos). Órgano es, pues, un centro de funciones establecido a efectos de división del trabajo, que forma parte de una persona jurídica, considerado como un centro de imputación o centro di relaciones. [...] En definitiva, el órgano no es más que el producto de la formalización jurídica de una realidad organizativa, o unidad funcional" (ALESSI, 1978).

5 En el derecho administrativo de los Estados nacionales en el marco de la centralización hay órganos concentrados y desconcentrados según el grado de proximidad con el Presidente, y en el esquema de la descentralización, además de los entes autárquicos, los no autárquicos y los autónomos.

6 En el derecho administrativo de los Estados nacionales es interesante en este punto resaltar la diferencia que existe en la práctica entre la creación de órganos, que generalmente está prevista en las Constituciones Nacionales como función del poder legislativo (crear y suprimir empleos) además de otorgarle atribuciones, es decir, competencias. En cambio, en relación a los entes la práctica demuestra que son creados muchas veces por decreto del Presidente.

7 El artículo 8, inciso c del POP establece como atribución del CMC "ejercer la titularidad de la personalidad jurídica del MERCOSUR". 
que los órganos de la estructura institucional solo gozan de capacidad jurídica para poder realizar los objetivos para los que fueron creados: abrir cuentas bancarias, suscribir contratos de contratación de servicios y obras, realizar gastos y pagos en ejecución del presupuesto asignado, etc. Por consiguiente, la estructura institucional del MERCOSUR, compuesta por órganos, responde a una técnica de distribución en un modelo de distribución de competencias concentrado. Así, las diversas competencias o funciones, creadas en los instrumentos jurídicos regionales, están respectivamente asignadas a determinados organismos que constituyen los llamados órganos institución (GAJATE, 2014) ${ }^{8}$. Estos, según MARIENHOFF, se componen de personas físicas que desarrollan actividades y expresan la voluntad del ente, aunque el órgano-institución es permanente y estable y no se identifica con las personas físicas que lo integran ${ }^{9}$ (MARIENHOFF, 1991). Es así que los órganos del MERCOSUR responden a una técnica de distribución de competencias de un modelo concentrado.

Ahora bien, para seguir analizando la estructura institucional del MERCOSUR, es de mencionar que la potestad para dictar normas sobre organización administrativa le corresponde, en principio, al $\mathrm{CMC}$, ya que está previsto entre sus funciones (art. 8. inc. f e inc. g POP) crear y suprimir órganos de la estructura institucional del MERCOSUR ${ }^{10}$. La distribución de competencias en esos órganos la realizan en forma conjunta el CMC y el Grupo de Mercado Común (GMC), y obedecen a las finalidades históricas de creación de este sistema de integración.

\subsection{BREVE RELATO HISTÓRICO SOBRE LA CREACIÓN DE ÓRGANOS EN EL MERCOSUR}

La creación de órganos en la estructura del MERCOSUR desde su concepción en el año de 1991 hasta la actualidad puede dividirse en las siguientes tres etapas: la primera, de creación de órganos netamente comerciales destinados a cumplir objetivos de esa índole, comprende los años 1991 a 2000; la segunda, marcada por la ampliación de las agendas y la mayor democratización del proceso de integración, comienza en 2008, con la elección popular de los representantes del PARLASUR por el pueblo paraguayo ${ }^{11}$, y se extiende hasta 2015 ; y una tercera

8 El término "institución" tiene origen indoeuropeo y posee dos significados: a) estar, permanecer, y b) poner, colocar, de lo que se deduce, "acción encaminada a hacer que algo no cambie, permanezca o sea estable".

9 Las principales teorías que justifican el accionar de las personas físicas como actos de los órganos a los que pertenecen son: la teoría del "mandato", la teoría de la "representación" y la teoría del "órgano".

10 El artículo 8 del POP establece que son funciones y atribuciones del Consejo de Mercado Común: "f) Crear reuniones de ministros y pronunciarse sobre los acuerdos que le sean remitidos por las mismas; g) Crear los órganos que estime pertinentes, así como modificarlos o suprimirlos".

11 La composición del Parlamento prevé la elección popular mediante voto directo, a pesar 
se iniciará con la elección de los representantes del pueblo por voto directo en todos los Estados del MERCOSuR. Como en las administraciones públicas nacionales, las instancias regionales están llamadas a guardar una correspondencia con las misiones o los fines para los cuales fueron creadas.

En la primer etapa, el fundador Tratado de Asunción, en su Capítulo II, se ocupó de la estructura orgánica estableciendo que la administración y ejecución de ese tratado y los acuerdos y decisiones que se adopten estarían a cargo de los siguientes órganos: Consejo de Mercado Común (CMC), Grupo de Mercado Común (GMC), los Subgrupo de Trabajo (SGT) que cree el GMC, y la Secretaría Administrativa; del mismo modo, en el Capítulo VI se refirió a la conformación de la Comisión Parlamentar Conjunta (art. 24 del Tratado de Asunción), y en el artículo 3 ibídem, a un régimen de solución de controversias. Con el Protocolo de Brasilia (PB), a finales del mismo año, se creó un régimen transitorio de solución de controversias tendiente a la constitución de tribunales arbitrales $a d$ boc $^{12}$. Esto significa que el Tratado de Asunción enunció una estructura sencilla, que apostaba más a una institucionalidad intergubernamental de perfil integracionista en materia solo comercial, con rasgos de orientación liberal (CAETANO, 2006), que gobernó en la primera etapa del MERCOSUR.

Luego, en diciembre de 1994 se firmó el Protocolo de Ouro Preto (POP), norma que en su artículo 2 precisó el carácter intergubernamental de los órganos y creó un nuevo órgano decisorio, la Comisión de Comercio del MERCOSuR (CCM), dependiente también de los poderes ejecutivos y de dos órganos consultivos, a saber, la Comisión Parlamentaria Conjunta (CPC) y el Foro Consultivo Económico Social. Además, se crearon instancias auxiliares dependientes del CMC como los comités técnicos y las reuniones de ministros.

A partir del relanzamiento del MERCOSUR en el año 2000, se inició una segunda etapa institucional, debido a la adopción de una agenda más amplia, no solo enfocada a fines comerciales ${ }^{13}$. Surgió así el Foro de Consulta y Concertación Política $(\mathrm{FCCP})^{14}$, y la Secretaría Administrativa se transformó en Secretaría

de que hasta el momento solo Paraguay ha cumplido la disposición, mientras que en los demás Estados Parte los parlamentarios son representantes de los poderes legislativos nacionales. Argentina aprobó la Ley 27.120 para en las elecciones de 2015 elegir de forma directa a los parlamentarios del MERCOSUR.

12 A pesar de que este protocolo fue aprobado para el período de transición, hasta la constitución definitiva requerida en el Tratado de Asunción, estuvo vigente hasta el año 2004, momento en que entró en vigencia el PO.

13 El relanzamiento del MERCOSUR, en el año 2000, incluyó en la CMC/DEC n. ${ }^{\circ}$ 25/00 el Perfeccionamiento del Sistema de Solución de Controversias entre los objetivos enunciados. Se instruyó al GMC, entre otras cosas, para que, mediante un Grupo Ad Hoc de Aspectos Institucionales, presente una propuesta integral de perfeccionamiento. Plazo prorrogado mediante la CMC/DEC n. ${ }^{\circ}$ 65/00, que creó un Grupo de Alto Nivel. 
Técnica (SM) ${ }^{15}$. Con posterioridad, el Protocolo de Olivos (PO) de 2002 creó el Tribunal Permanente de Revisión (TPR) ${ }^{16}$, la Comisión de Representantes Permanentes del MERCOSUR (CRPM) ${ }^{17}$, que se instituyó dentro de la órbita del $\mathrm{CMC}$, y también el Foro Consultivo de Municipios, Estados Federados, Provincias y Departamentos del MERCOSUR ${ }^{18}$, y el Parlamento del MERCOSUR ${ }^{19}$.

En ese sentido, a partir del año 2003, con la ampliación de las dimensiones en la agenda del MERCOSUR, se revitalizó el proceso de integración con la creación de los siguientes órganos: el Centro MERCosur de Promoción del Estado de Derecho (CEMPED $)^{20}$, con la finalidad de afianzar el desarrollo del Estado y la gobernabilidad democrática, el Instituto Social del MERCOSUR (ISM) ${ }^{21}$, con el fin de contribuir a la consolidación de la dimensión social y cooperar en el diseño de políticas sociales; el Observatorio de la Democracia del MERCOSUR $(\mathrm{ODM})^{22}$, coordinado por el CEMPED y la CRPM, para cumplir los objetivos del Protocolo de Ushuaia sobre Compromiso Democrático y realizar el seguimiento electoral en los Estados parte; y el Instituto de Políticas Públicas de Derechos Humanos del MERCOSUR (IPPDH) ${ }^{23}$, con la función de realizar el diseño y seguimiento de las políticas en derechos humanos y el fortalecimiento del Estado de derecho.

Por último, en el año 2010 se creó el Alto Representante del MERCOSUR $(\mathrm{ARGM})^{24}$, designado por el $\mathrm{CMC}$, siendo una personalidad política destacada con la función principal de representar al MERCOSUR, con mandato del CMC, y contribuir a la coordinación de los órganos de la estructura del MERCOSUR. Dentro de la órbita del ARGM se creó la Unidad de Participación Social (UPS) ${ }^{25}$, con la tarea de trabajar con las instancias sociales para fortalecer la participación social. Esta última integrada por un coordinador designado por el CMC.

La tercera etapa de la institucionalidad comenzará cuando la elección de los representantes del pueblo sea por voto directo en todos los Estados del MERCOSUR.

MERCOSUR/CMC/DEC n. ${ }^{\circ}$ 30/02.

La Secretaría del TPR y la SM están integradas por funcionarios del MERCOSUR, y dirigidas por un Secretario, en el primer caso, y un Director, en el segundo, designados por el CMC, con la salvedad de que en el caso del Secretario del TPR se realiza un concurso público. Además estos dos órganos cuentan con presupuesto propio.

MERCOSUR/CMC/DEC n. ${ }^{\circ} 11 / 03$.

MERCOSUR/CMC/DEC n. ${ }^{\circ} 22 / 04$.

MERCOSUR/CMC/DEC n. ${ }^{\circ} 49 / 04$ y n. ${ }^{\circ} 23 / 05$.

MERCOSUR/CMC/DEC n. ${ }^{\circ} 24 / 04$.

MERCOSUR/CMC/DEC n. ${ }^{\circ} 3 / 07$.

MERCOSUR/CMC/DEC n. ${ }^{\circ} 5 / 07$.

MERCOSUR/CMC/DEC n. ${ }^{\circ}$ 14/09.

MERCOSUR/CMC/DEC n. ${ }^{\circ}$ 63/10.

MERCOSUR/CMC/DEC n. ${ }^{\circ}$ 65/10. 


\subsection{ClasificaCión DE los ÓRGANOS DE LA ESTRUCTURA ORGANIZACIONAL DEL MERCOSUR}

El MERCOSUR crea un sistema intergubernamental conforme al cual la delegación de competencias en instituciones comunes es bastante reducida (RuIZ DíAZ LABRANO, 1995), preservando el rol preponderante del Estado miembro en el proceso de integración. Ahora bien, dentro de ese marco cabe diferenciar los órganos creados por el MERCOSUR con cierto grado de autarquía ${ }^{26}$ respecto de los órganos políticos de los Estados. Para analizar la estructura organizativa del MERCOSUR es posible diferenciar sus órganos en función de su composición y de sus funciones:

1) En cuanto a su composición, se cuentan los que tienen capacidad decisoria, los auxiliares, y los conformados por funcionarios del MERCOSUR pero que poseen autonomía prespuestal (SUÑ̃é, 2014):

Son órganos con capacidad decisoria el CMC, que es el órgano superior y conductor político del proceso de integración, compuesto por los ministros de Relaciones Exteriores o de Economía; el GMC, que es el órgano ejecutivo, integrado por funcionarios de esas carteras de los gobiernos, quienes participan activamente en la toma de decisiones; y la CCM, encargada de asistir al GMC en la conducción de la política comercial. Estos órganos emiten decisiones, resoluciones y directivas, respectivamente. Como vemos, salvo algunas pocas instituciones en el MERCOSUR, los funcionarios son representantes de los propios gobiernos, con los vicios que ello puede traer en relación a la toma de decisiones, ya que tiene dependencia orgánica y funcional con respecto a aquellos (SCOTTI, 2010).

Con relación a los órganos auxiliares se tiene que son los órganos subordinados a los órganos con capacidad decisoria. Son auxiliares, en la medida en que se trata de órganos técnicos o especializados en diferentes temáticas y asesoran a los órganos con capacidad decisoria, tales como los subgrupos de trabajo, los comités técnicos, las reuniones especializadas, los grupos ad hoc, etc. Se componen por funcionarios que pueden pertenecer a distintos ministerios o secretarías de gobierno, por lo que reciben instrucciones de sus gobiernos. Son órganos dependientes del GMC: los Grupos, que son los órganos que ejercen atribuciones específicas propias del funcionamiento del $\mathrm{GMC}_{i}$ los Sub Grupo de Trabajo (SGT), que son órganos técnicos creados para la negociación permanente de políticas públicas y para la coordinación de este tipo de políticas en el ámbito del MERCOSUR (p. ej., industria, energía,

26 Este concepto lo utilizamos a los largo de la exposición, y se refiere a la autonomía en relación a los órganos de los Estados Parte. 
inversiones, contrataciones públicas, etc.); además, los Grupos Ad Hoc (GAH), que son órganos temporarios creados para temas específicos y por un plazo de tiempo determinado (p. ej., de superación de asimetrías, de biocombustibles, etc.); las Reuniones Especializadas (RE), como su nombre lo indica, son órganos permanentes especializados para desarrollar temáticas atinentes a los temas específicos que les ha asignado el GMC en su creación (p. ej., reuniones de ministerios públicos, de organismos gubernamentales de control interno, de turismo, etc.). Todos ellos son órganos de asistencia al GMC, por lo cual este ejerce la función de coordinar y orientar las tareas de los SGT y considerar las recomendaciones por ellos transmitidas (relación de tutela) ${ }^{27}$. Son órganos dependientes del CMC los Grupos de Trabajo permanentes o Ad Hoc o Grupos de Alto Nivel, además de las Reuniones de Ministros (se expresan mediante "acuerdos"), y los Comités Técnicos. La relación del CMC con estos órganos es de tutela. Y, finalmente, la CCM crea los Comités Técnicos (CT) necesarios para el cumplimiento de sus funciones, incluso para la consideración de las reclamaciones, y establece las condiciones de operaración y supervisión de su actividad. Los CT no tendrán facultades decisorias y deberán informar y presentar sus recomendaciones y dictámenes a través de la Presidencia Pro Tempore de la CCM.

Trátandose de los órganos compuestos por funcionarios del MERCOSUR ${ }^{28}$ y que tienen presupuesto propio ${ }^{29}$, cabe indicar que en ellos los funcionarios no dependen ni fueron designados por los órganos políticos de los Estados, ni reciben instrucciones de gobierno alguno. El modo de ingreso a estos órganos es mediante concurso público regional. Es el caso de la SM, la Secretaría del Tribunal Permanente de Revisión (ST del TPR), el ISM, el IPPDH, etc. ${ }^{30}$. En general, estos órganos están encabezados por un director o secretario que es propuesto, elegido y designado por el $\mathrm{CMC}^{31}$. No está prevista la participación de los funcionarios del MERCOSUR en ninguna reunión de alguno de los órganos decisorios, salvo de los directores o secretarios, con voz, pero sin voto.

28 El concepto de funcionario del MERCOSUR se encuentra definido en la GMC/RES n. ${ }^{\circ} 3 / 12$ y el régimen de carrera se encuentra establecido en la GMC/RES n. ${ }^{\circ} 4 / 12$ y n. ${ }^{\circ} 6 / 13$.

El concepto de autonomía conlleva una variante a la tradicional del derecho administrativo.

Estos últimos órganos se componen de la siguiente manera: el CEMPED y ODM se integran por un representante por cada Estado Parte, los cuales conforman un comité coordinado por un representante en ejercicio de la presidencia. El ISM y el IPPDH, conformados por funcionarios del MERCOSUR en equilibrio de nacionalidades, son dirigidos por un Director Ejecutivo, en el caso del ISM, y por un Secretario Ejecutivo, en el caso del IPPDH, ambos designados por el CMC.

31 Ya mencionamos la salvedad del cargo de Secretario del TPR, en el que la elección tiene un procedimiento especial previsto en la normativa MERCOSUR que consiste en un concurso público. Ver MERCOSUR/RES/GMC n. ${ }^{\circ}$ 66/05. 
En cuanto a sus funciones, los órganos del MERCOSUR pueden ser ${ }^{32}$, en primer lugar, órganos consultores, como el Parlamento y el Foro Económico y Social. Asimismo, se encuentran los órganos decisorios, como CMC, GMC, CCM, con capacidad de crear normativa MERCOSUR, esto es, decisiones, resoluciones y directivas, respectivamente. Al lado de estos se encuentran los órganos participativos o de representación, como el Foro Económico y Social, la Cumbre Social ${ }^{33}$, y los de elección popular, como el Parlamento. Los órganos jurisdiccionales son: el Tribunal Permanente de Revisión (TPR), órgano jurisdiccional por excelencia, integran también la estructura del MERCOSUR. Este tribunal es competente en sede consultiva o contenciosa para interpretar y decidir sobre la normativa del MERCOSUR, y está compuesto por un árbitro proveniente de cada Estado Parte ${ }^{34} ;$ los Tribunales ad hoc (TAH), que entienden en las controversias entre los Estados Parte y se conforman por árbitros elegidos entre las listas de árbitros proporcionadas por los Estados, siendo sus decisiones revisables ante el TPR; el Tribunal Administrativo Laboral (TAL) ${ }^{35}$, previsto como una única instancia jurisdiccional para resolver las reclamaciones administrativo-laborales de los funcionarios MERCOSUR y los contratados para obras o servicios una vez agotadas las vías administrativas correspondientes ${ }^{36}$. El mismo está compuesto por funcionarios de los Estados indicados por el Estado Parte y designados por el GMC para cumplir esas funciones ${ }^{37}$. Es necesario indicar en este punto que el procedimiento previsto para reclamar ante el TAL evidencia la carencia de normas de organización administrativas en la estructura institucional del MERCOSUR, ya que las pocas que existen solo enuncian el agotamiento de las instancias administrativas a pesar de que no existe una norma de procedimientos administrativos que establezca el modo de agotar las instancias ${ }^{38}$. Podríamos

32 Se puede utilizar como referencia para una clasificación la desarrollada por GARCíA TREVIJANO FOS.

33 Institucionalizadas en 2012.

34 De conformidad con el Protocolo de Olivos sobre Solución de Controversias en el MERCOSUR, se compone además por un Quinto Árbitro elegido por unanimidad entre los Estados Parte. No obstante, el Protocolo Modificatorio del Protocolo de Olivos, que prevé la adhesión de nuevos Estados como miembros plenos del MERCOSUR, prevé la figura del árbitro adicional.

GMC/RES n. ${ }^{\circ}$ 54/03

36 Lamentablemente no fue prevista la posibilidad de que los funcionarios del MERCOSUR recurran las decisiones de esta instancia administrativa ante el TPR. Creemos que debe otorgarse esta posibilidad de recurrir, ya que se trata de reclamos exclusivos en materia administrativa laboral, y el TPR es la última instancia para decidir sobre toda la normativa del MERCOSUR, tal como quedó establecido con el Laudo 1/2012, que recuerda lo establecido en el párrafo primero del artículo1 del PO.

37 Resultan al menos intrigantes estas ausencias de división de poderes en algunos órganos, sobre todo de la mirada del derecho administrativo.

38 Ahora resulta interesante la aparición en la norma de la expresión "agotar la vía administrativa" cuando para ello resulta al menos necesario saber cómo se agota la vía administrativa, 
interpretar que en estructuras con funcionarios propios se agotan en el director del órgano, y que en los órganos dependientes o auxiliares lo hacen en los órganos con capacidad decisoria.

Todavía desde un punto de vista funcional, es posible encontrar los órganos de control, y algunos que entre sus funciones tienen competencias de control. Es el caso del Parlamento del MERCOSUR, el cual, entre sus atribuciones, está encargado de controlar el presupuesto. Cabe aclarar que las funciones jurisdiccionales, legislativas o de control también son propias de los tres órganos con capacidad decisoria. Como se señalaba, estos órganos están conformados por representantes de los gobiernos nacionales, lo que permite controlar todo el proceso de integración, circunstancia que es propia de un sistema intergubernamental ${ }^{39}$.

Adicionalmente están los órganos ordinarios o extraordinadios, según si son órganos permanentes y usuales que desempeñan funciones específicas, o bien órganos destinados a cumplir funciones especiales por un tiempo determinado, con funciones provisorias (ALESSI, 1949). Existen en el MERCOSUR ambos tipos de órganos: los ordinarios o permanentes ya los hemos enunciado en el desarrollo histórico de su creación; y los extraordinarios son los diversos órganos creados para cumplir funciones específicas, como el Grupo Ad Hoc para estudiar el ingreso de Ecuador al MERCOSUR ${ }^{40}$.

\subsection{TOMA DE DECISIONES. CARÁCTER INTERGUBERnAMENTAL}

La particularidad de un sistema intergubernamental consiste en que mientras en la supranacionalidad las instituciones tienen potestad autónoma, por encima de los Estados, para el cumplimiento de funciones ejecutivas, legislativas y judiciales, en el modelo intergubernamental la delegación de competencias en instituciones comunes es mínima (Ruiz DíAZ LABRANO, 1995). La toma de decisiones en el MERCOSUR se hace por consenso y unanimidad, lo que preserva el rol preponderante del Estado. Y esta es la característica más trascendental de las estructuras organizativas del MERCOSUR: el carácter intergubernamental y el principio general de toma de decisiones por consenso y quórum de todos los miembros presentes. Todo Estado Parte tiene, en efecto, posibilidad de vetar

qué principios entran en juego, qué plazos para resolver las reclamaciones existen, para lo que el organigrama institucional y una norma de procedimiento resultarían a simple análisis indispensables. Por ello, entendemos que se previeron procedimientos administrativos para la incipiente estructura administrativa, pero sin el recaudo de una norma interna que refiera, al menos, el modo de agotar instancia.

39 Para CZAR de ZaLduendo esta situación se debe a dos razones: los fracasos de experiencias latinoamericanas anteriores frente a intentos ambiciosos de supranacionalidad, y los controles presupuestarios de los gobiernos para evitar excesos (CZAR DE ZALDUENDO, 2010). A lo que agregamos el evidente control político del proceso. 
una normativa, posibilitando así las abstenciones facultativas (MARIENHOFF, 1991). El quórum se compone solo por representantes gubernamentales, no teniendo voto los directores o secretarios ejecutivos de los órganos, ni el Alto Representante del MERCOSUR, y menos aún los funcionarios del MERCOSUR, que ni siquiera participan de las reuniones. Por este motivo los órganos del MERCOSUR no tienen autonomía, ostentando dependencia orgánica y funcional respecto de los representantes de los Estados nacionales. Conforme a esto, el único órgano con autonomía en sus decisiones es el TPR, órgano de solución de controversias del MERCOSUR, ya que las decisiones de los árbitros son obligatorias para los Estados Parte.

\section{PRINCIPIOS DE ORGANIZACIÓN ADMINISTRATIVA APLICADOS EN LA ESTRUCTURA DEL MERCOSUR}

Entendemos los principios como las "pautas o patrones que actúan como soporte lógico y valorativo para la creación de las normas positivas, de carácter público o privado y tanto de alcance general como particular, así como guía

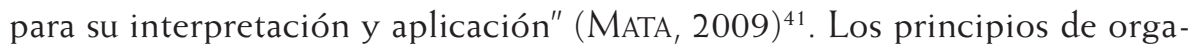
nización administrativa son las pautas para la creación de normas de alcance particular y general en materia de organización administrativa cuya función consiste en servir de guía para la interpretación y aplicación en una estructura institucional. Para GiANNINI la organización administrativa no es propia solo de los Estados y de los entes públicos; la tienen los entes internacionales y supraestatales, iglesias o grupos empresariales. Hay, incluso, sociedades comerciales que tienen organizaciones supraestatales, y organizaciones de entes sindicales también supraestatales (GIANNINI, 1991).

\subsection{Características de las estructuras institucionales}

En relación con la estructura del órgano, las organizaciones son clasificadas por la doctrina, entre ella MARIENHOFF, SANTAMARía PASTOR, TREVIJANO Fos, con algunas diferencias, en burocrática, colegiada y autárquica, y en cuanto a la actividad desplegada, en términos de relaciones interorgánicas o interadministrativas.

La administración burocrática es aquella donde las funciones están asignadas a personas físicas que actúan individualmente, y el principio que las rige

41 Además sostiene que los principios implican estándares primarios, bases, fundamentos, puntos de partida, razones o proposiciones fundamentales, a partir de los cuales comienza el análisis científico, pudiéndose diferenciar entre los que son comunes a todo saber y los que son específicos a cada disciplina del conocimiento. En este trabajo abordaremos principios o estándares de organización administrativa, específicamente. 
es la jerarquía. El órgano burocrático actúa en forma permanente o continua. El principio de jerarquía se da en la relación de supremacía entre superiores e inferiores dentro de una estructura organizativa, en la cual los superiores imparten órdenes y los subordinados o inferiores las cumplen. Dentro de la administración solo quedan fuera del orden jerárquico los órganos de control, los consultivos y los que ejercen funciones jurisdiccionales. La jerarquía se ordena en líneas y grados: las líneas implican la serie de funcionarios unidos por relaciones de subordinación en forma vertical, y los grados son los puntos que ocupan los funcionarios en la línea vertical (MARIENHOFF, 1991). Así por ejemplo, en el MERCOSUR los órganos con presupuesto propio que siguen una organización burocrática emplean la siguiente línea: director, coordinador, asesor técnico, técnico, asistente técnico, personal de apoyo ${ }^{42}$.

En lo que respecta a la administración colegiada, se tiene que es aquella donde el ejercicio de la función está encomendado simultáneamente a distintas personas físicas, que actúan en un pie de igualdad, sin perjuicio de quien dirija o presida el órgano (presidente, rector, director, gerente, etc.). La voluntad de estos órganos se expresa en actos denominados deliberaciones. De las reuniones se elaboran actas (MARIENHOFF, 1991) ${ }^{43}$. La composición de los órganos se da en número impar para facilitar la decisión por mayoría. A veces estos órganos exigen un determinado número de miembros para sesionar, lo que se denomina quórum. La relación entre ellos la rige el principio de coordinación, estando los órganos en pie de igualdad para la toma de decisiones.

La administración autárquica es la que realiza el Estado a través de uno o varios órganos dotados de personalidad jurídica. Se la suele llamar administración descentralizada ya que no es directamente el Estado, sino el órgano que así se crea, quien desarrolla la actividad. La administración autárquica dispone

42 Algunos órganos presentan en su estructura analistas técnicos y técnicos senior.

43 Es interesante detallar algunas cuestiones de los órganos colegiados, ya que es un modelo elegido por los órganos del MERCOSUR, y en el cual no fueron previstas algunas cuestiones en las que el derecho administrativo tiene más experticia. Puede ocurrir, por ejemplo, que alguno o algunos de los integrantes del órgano colegiado se abstengan de votar, situación en la que MARIENHOFF distingue el motivo que originó esa abstención, entre el hecho de que la misma responda o no a una razón (lo que llama de abstención "obligatoria") y los supuestos de abstención "facultativa", según que los miembros permanezcan en las sesiones o se retiren de ella. Las soluciones propuestas por MARIENHOFF en los supuestos de abstención obligatoria consisten en que los abstinentes, aunque se hallen presentes en el recinto, no deben computarse ni a los efectos de la validez de la reunión ni o a los efectos de la votación, porque están jurídicamente como ausentes. En cambio, sostiene el autor, diferente es la situación de quienes se abstienen por propia voluntad, sin causa jurídica. En estos casos se computan a los efectos de validez de la reunión, y votación. Además el autor en cita contempla la situación de los supuestos de abstención facultativa, sin causa jurídica, y solo como medio de coerción para lograr un propósito, en cuyo caso si el miembro se abstiene, a pesar de que se retire del recinto, debe ser tenido en cuenta a los efectos del quórum requerido para que la votación sea válida. Se considera como presente. 
de libertad funcional, a pesar del control que sobre dicho organismo descentralizado ejerciten las autoridades superiores centralizadas. En general cuenta con personalidad jurídica de derecho público interno, patrimonio afectado al cumplimiento de los fines encomendados, y fin público.

Podemos decir entonces que la creación de la estructura institucional del MERCOSUR pareciera ser una estructura de órganos colegiados, compuestos por representantes de todos los Estados en aquellos órganos con capacidad decisoria y en los auxiliares o dependientes de los órganos decisorios. La presidencia de los órganos colegiados se ejerce en forma rotativa siguiendo el orden alfabético.

En relación con los órganos compuestos por funcionarios del MERCOSUR y con presupuesto propio, son dirigidos por personas físicas designadas por el $\mathrm{CMC}$, teniendo muchas veces características burocráticas de índole jerárquica. El único órgano en que pareciera haber mayor autarquía es el TPR, en el que deciden los árbitros y cuyos laudos son obligatorios.

Respecto de la actividad desplegada, se diferencian: las relaciones interadministrativas, que pueden darse en las relaciones entre órganos con personalidad jurídica, y entre la administración centralizada y una entidad autárquica, las relaciones interorgánicas, que pueden darse en las relaciones entre meros organismos o reparticiones de la administración centralizada $a_{i}$ las relaciones entre órganos de una misma persona pública estatal. La gran diferencia radica en que en las relaciones interadministrativas las relaciones son entre sujetos de derecho, y en las relaciones interorgánicas entre meros órganos. Los actos de las relaciones interadministrativas corresponden además a la actividad externa de la administración, en tanto que los actos de las relaciones interorgánicas perteneces a la actividad interna de la administración. Ello es así porque los vínculos jurídicos solo pueden establecerse entre sujetos de derecho, característica que no ostentan los órganos que integran un mismo ente. Así, en ejercicio de sus funciones, los órganos establecen entre sí vínculos de cooperación y de colisión. No sería posible sostener una controversia o litis en materia de relaciones interorgánicas, pues para ello faltaría la personalidad jurídica de los respectivos órganos, pero sí realizar gestiones de carácter administrativo interno o prever mecanismos para la solución de conflictos. En cambio, cuando las relaciones interadministrativas, se da entre órganos dotados de personalidad jurídica la jurisdicción contenciosa será permitida.

En cuanto al MERCOSUR, no está prevista una modalidad para solucionar los conflictos intra MERCOSUR. Es decir que no está previsto en el sistema de solución de controversias del MERCOSUR el modo de solución de conflictos que se susciten en el seno del MERCOSUR, salvo en el caso de las Reuniones de Ministros $^{44}$. Tan es así, que no está previsto que en los conflictos que pudieran

44 Previsto en la MERCOSUR/CMC/DEC n. ${ }^{\circ}$ 26/05 sobre Procedimiento especial del Protocolo de Olivos para la Solución de Controversias originadas en acuerdos emanados de reuniones de ministros del MERCOSUR. 
surgir entre a) distintos órganos del MERCOSUR, b) un órgano de la estructura organizativa del MERCOSUR y un Estado Parte ${ }^{45}$, o c) la posibilidad de interponer recurso de revisión sobre las decisiones del TAL ${ }^{46}$ ante el TPR, órgano con competencia en toda la normativa del MERCOSUR (BARREIRA, 2008). De todos estos órganos solo participan del sistema de solución de controversias: los órganos con capacidad decisoria, en las etapas prejurisdiccionales del Protocolo de Olivos o del Anexo al Protocolo de Ouro Preto; los TAH, que tienen recurso de revisión al TPR; y el TAL, que es la única instancia jurisdiccional para resolver las reclamaciones administrativo-laborales de los funcionarios de las instituciones del MERCOSUR, o entre los contratados para obras o servicio una vez agotadas las vías administrativas correspondientes. Creemos que el TPR debería tener un mecanismo de solución de conflictos intra MERCOSUR, más allá de la posibilidad de emitir opiniones consultivas, sistema en el cual están legitimados los órganos con capacidad decisoria, únicamente, y el Parlamento.

\subsection{PRinCiPIOS DE ORGANIZACIÓN EN DERECHO ADMINISTRATIVO PRESENTES EN EL MERCOSUR}

En el MERCOSUR existen los requisitos para que sean aplicables principios de organización administrativa. Veremos entonces si esos principios aplicables son los del derecho administrativo o si los principios que rigen la estructura institucional del MERCOSUR presentan algunas particularidades.

Analizando los principios de derecho administrativo estudiados en este trabajo llegamos a la conclusión de que son aplicables los siguientes: el modelo estructural el MERCOSUR, compuesto por órganos y no por entes responde a una técnica de distribución de competencias de un modelo concentrado. Solo tiene personalidad jurídica la organización regional en sí, ejercida dicha titularidad por el CMC salvo expreso mandato al Alto Representante, mientras que los órganos de la estructura institucional únicamente gozan de capacidad jurídica. Es decir que la estructura institucional del MERCOSUR, según el derecho administrativo, corresponde a una técnica de distribución de competencias de un modelo concentrado, y esa estructura institucional concentrada del MERCOSUR está compuesta por órganos con capacidad decisoria y sus auxiliares de carácter colegiado intergubernamentales.

Ahora bien, los órganos compuestos por funcionarios del MERCOSUR y que tienen presupuesto propio tienen características burocráticas con presencia

45 Se podría dar, por ejemplo, en relación a la normativa del MERCOSUR, un conflicto sobre los fondos de convergencia estructural, que aunque se prevean órganos para la interpretación del Reglamento, la última palabra sobre la interpretación de la normativa MERCOSUR debería ser del TPR. 
del principio de jerarquía, y los órganos jurisdiccionales muestran atisbos de autarquía.

En relación con la función del órgano, desde la óptica del derecho administrativo, podemos advertir: una administración activa, que decide y ejecuta funciones que en el MERCOSUR desempeñan el GMC como órgano ejecutivo y el CMC como órgano conductor del proceso; una administración interna, como actividad que el órgano administrador realiza para su propia organización, en la cual no entra en relación con terceros sino que está destinada al funcionamiento del ente, y que se observa en las normativas dictadas que reglamentan el funcionamiento interno de la organización y que no requieren incorporación por los ordenamientos jurídicos de los Estados Parte; y una administración externa, cuya actividad se desarrolla en su vinculación con terceros, siendo su finalidad la de satisfacer intereses públicos (esta función la desarrolla el CMC, que ejerce la titularidad de la personería jurídica). Advertimos, además, actividad discrecional, cuando la conducta de la administración no está determinada por leyes, sino por la finalidad legal a cumplir, en cuyo caso son los órganos quienes deciden, de entre un abanico de posibilidades legales, cuál es la más conveniente: ejemplo, el TAL $;$ y actividad reglada, cuando la administración actúa de acuerdo a normas jurídicas, correspondiendo al funcionamiento cotidiano de los órganos del MERCOSUR.

Siguiendo la clasificación de los órganos del derecho administrativo, ellos pueden ser: en cuanto a su composición: de capacidad decisoria, auxiliares, conformados por funcionarios del MERCOSUR y con presupuesto propio; en cuanto a sus funciones: consultores, decisorios, participativos, jurisdiccionales, de control, ordinarios o extraordinarios. Todas estas categorías se encuentran presentes en la estructura institucional y encuadran perfectamente con las clasificaciones de órganos de una estructura organizacional del derecho administrativo.

De todos modos, creemos que a la estructura institucional del MERCOSUR le falta desarrollar un órgano de contralor, que tenga como objeto verificar la legitimidad e incluso la oportunidad o conveniencia de los actos. Sea de tipo financiero, es decir referirse a los actos que realicen los órganos administrativos con posterioridad respecto de la emisión del acto, o de carácter represivo, o referirse a la legitimidad o a la oportunidad o conveniencia de un acto ${ }^{47}$. Hasta que no se apruebe el prepuesto único del MERCOSUR ${ }^{48}$, cada presupuesto

Cuenta con funciones de control interno el Grupo de Asuntos Presupuestarios, dentro de la órbita del GMC, que controla el presupuesto, pero no se cuenta con un grupo especializado para desarrollar las auditorías externas que los órganos que actualmente contratan a auditorías privadas.

48 En el MERCOSUR/GMC/ACTA n. ${ }^{\circ}$ 01/13 el GMC recibió un informe sobre los resultados de la v Reunión Extraordinaria del Grupo de Asuntos Presupuestarios (GAP), celebrada el 5 de junio de 2013, en Montevideo, sobre el estado de la situación y los lineamientos para la normativa de Presupuesto Único del MERCOSUR, y prestó su conformidad para que el GAP se aboque a la elaboración de dicha normativa con base en tales lineamientos. 
de las instituciones se gestiona en forma separada ${ }^{49}$, rigiendo las MERCOSUR/ GMC/RES n. ${ }^{\circ}$ 50/03 y n. ${ }^{\circ}$ 15/12 que establecen las normas básicas de ejecución presupuestal, contabilidad patrimonial y financiera de todas las instituciones del MERCOSUR con presupuesto propio ${ }^{50}$. Las auditorías de esos presupuestos son realizadas por auditores privados externos contratados a tal efecto ${ }^{51}$; sin embargo, creemos que el control externo de los órganos del MERCOSUR debe ser público, por tratarse de presupuesto público de los Estados Parte ${ }^{52}$. No obstante, resaltamos como positivos los cambios orientados a mejorar la participación ciudadana y la transparencia de las instituciones ${ }^{53}$. Fue además asignada al Parlamento del MERCOSUR la competencia de control del presupuesto.

Pero como las relaciones desplegadas se dan en gran medida en la estructura institucional del MERCOSUR por la vía de relaciones interorgánicas, lo que implica una sola voluntad, una sola persona jurídica, no pudiendo generarse una litis pero sí conflictos, las relaciones entre esos órganos deberían contar con un marco natural para la superación de conflictos.

49 El mecanismo establecido actualmente consiste en que los proyectos de presupuesto de las instituciones deben elevarse a consideración del GMC en la última reunión ordinaria de cada año para el ejercicio del año siguiente. El grupo de trabajo que analiza los asuntos presupuestarios es el Grupo de Asuntos Presupuestarios (GAP), órgano dentro de la órbita del GMC. El presupuesto se compone por aportes que los Estados Parte efectúan trimestralmente en tres o cuatro cuotas conforme ciertos plazos, modificados por al GMC/ RES n. ${ }^{\circ} 15 / 12$. En general el aporte a las instituciones del MERCOSUR se realizaba en forma igualitaria, es decir que los cuatro Estados aportaban la misma suma de dinero. Las últimas instituciones creadas, el ISM y el IPDDHH, tienen aportes diferenciando el país. Es decir que se adopta un criterio más equitativo.

50 Si bien esta norma se refiere a la SM, se extiende su aplicación a los demás órganos a los que se les ha previsto un presupuesto propio, ya que en este último tiempo han sido creados órganos con estas características, más allá de la SM. Por el artículo 34 POP se reconoce personalidad jurídica al MERCOSUR al establecer: "El Mercosur tendrá personalidad jurídica de Derecho Internacional". Y el artículo 35, como consecuencia de ello, dispone: "El Mercosur podrá, en el uso de sus atribuciones practicar todos los actos necesarios para la realización de sus objetivos, en especial contratar, adquirir o enajenar bienes muebles e inmuebles, comparecer en juicio, conservar fondos y hacer transferencias".

51 En 1991, las entidades fiscalizadoras superiores (EFS) de los Estados originarios del MERCosur: la Auditoría General de la Nación (Argentina), el Tribunal de Cuentas de la Unión (Brasil), la Contralaría General (Paraguay) y el Tribunal de Cuentas (Uruguay), crearon una Comisión Permanente Multinacional, con vistas a ejercer la auditoría externa del MERCOSUR.

52 En el caso del FOCEM, que prevé importantes aportes de us\$1 billón cada diez años, y a pesar de los procedimientos administrativos previstos del FOCEM, en los que se controla el uso de los fondos y se dispone una rendición de cuentas, se contratan auditorías externas, sin existir previsión para que pueda ejercer acción fiscalizadora un organismo público regional. Por MERCOSUR/DEC/CMC n ${ }^{\circ} 45 / 04$

53 MERCOSUR/CMC/DEC n. ${ }^{\circ}$ 2/13 de Rendición Social de Cuentas en el MERCOSUR, y MERCOSUR/ CMC/DEC n. ${ }^{\circ} 4 / 13$ de Derecho a solicitar información a los órganos del MERCOSUR. 


\subsection{Principios DE ORGanización ADMINISTRATIVA PROPIOS DEL MERCOSUR}

Ahora bien, como vimos, son varios los principios y elementos que la estructura institucional del MERCOSUR aplica en su funcionamiento que responden a los principios de organización administrativa del derecho administrativo. No obstante, sería un error pretender trasladar los principios que rigen las organizaciones administrativas internas de los Estados Parte, en forma supletoria, sin filtrar aquellas características que por la naturaleza de estas instituciones regionales serían inaplicables. Por lo que la adaptación de principios debe darse por analogía, respetando las particularidades del derecho de la integración ${ }^{54}$.

GONZÁLEZ MORAS diferencia dos tipos de principios de organización administrativa, los referentes a la aplicación del derecho comunitario (o de la integración) y los vinculados a la organización administrativa interna. Los primeros serían los principios aplicables a los órganos del MERCOSUR, y los segundos los principios del derecho interno, propios de los Estados Parte. Creemos que la diferenciación seguirá subsistiendo porque los fines de unos y otros hacen que sea incompatible compartir los mismos principios (GONZÁLEZ MORAS, 2004). Este autor enuncia algunos que considera principios de organización administrativa presentes en estas instituciones:

1. Administración indirecta: este principio significa que los Estados se comprometen a hacer cumplir las normas del MERCOSUR a través de sus instituciones internas, adoptando las medidas necesarias para ello.

2. Cooperación: se refiere a la cooperación de hacer cumplir las normas acordadas y de no aplicar el derecho contrario a ellas.

54 El que preferimos llamar derecho de la integración, ya que en el MERCOSUR contamos con un derecho de la integración y no con un derecho comunitario, que es una etapa más profunda de la integración. El TPR ha tenido oportunidad de definir a este conjunto normativo en el Considerando 24 de la OC $n .^{\circ} 1-2008$, al establecer que se entiende por derecho del MERCOSUR: "un conjunto de normas establecido por voluntad de los Estados, plasmado en fuentes convencionales como los tratados-partiendo del propio TA y del POP, incluyendo otros instrumentos de carácter originario, como lo es también el PO- que forjan la estructura misma del MERCOSUR en la medida que establecen las normas, delinean los principios, indican los objetivos y los mecanismos fundamentales para alcanzarlos, crean los órganos comunes y determinan su competencia dotando a algunos de capacidad normativa, de cuyo ejercicio surgen las normas denominadas 'derivadas'. Todo ello constituye un cuerpo normativo vivo, de naturaleza especial y de jerarquía diversa, que se convierte en obligatorio como parte del ordenamiento jurídico de cada Estado Parte desde su incorporación o internalización, acto del cual derivan derechos y obligaciones": Opinión Consultiva 1/2008, "Sucesión CARLOS SCHNEK y otros c/ Ministerio de Economía y Finanzas y otros. Cobro de pesos", cursada por la Suprema Corte de Justicia de la República Oriental del Uruguay con relación a los autos del Juzgado Letrado de Primera Instancia en lo Civil de $1^{\text {er }}$ turno IUE 2-32247/07. Disponible en: http://www.tprmercosur.org/es/docum/opin/ OpinCon_01_2008_es.pdf 
Principios de organización administrativa en la estructura institucional del MERCOSUR 229

3. Autonomía: se relaciona con el principio de administración indirecta, en el sentido de que la ejecución de las normas se realiza por el Estado. Esto se debe a que el MERCOSUR no cuenta con un aparato organizacional suficiente como para cumplir los compromisos asumidos a través de sus propias instituciones y procedimientos. Un ejemplo es el Código Aduanero del MERCOSUR (CAN) ${ }^{55}$, en el que se prevé la utilización de los procedimientos utilizados por las Aduanas de cada Estado.

A estos principios enunciados por el autor podemos agregar los que se considera que son también verdaderos principios de organización administrativa:

4. Equilibrio: si la estructura administrativa se basa en la coordinación y la división del trabajo especializado, cada institución es dirigida por una autoridad cuya designación sigue el orden alfabético, del mismo modo que rotan las Presidencias Pro Tempore (PPT). Los órganos decisorios rotan en su conducción del mismo modo que lo hace la PPT, lo que implica que cada país tenga la presidencia por seis meses. Además, existe equilibrio de nacionalidad en las personas físicas que dirigen los órganos con presupuesto y funcionarios del MERCOSUR, como en la composición interna de cada órgano, en la que existe equivalente número de nacionales. Se previó, por ejemplo, la incorporación de funcionarios venezolanos en los órganos con funcionarios del MERCOSUR y presupuesto propio ${ }^{56}$

5. Consenso: esta forma de decidir que coloca a los países en pie de igualdad con un voto cada uno y por consenso responde al modelo intergubernamental. Si bien hace que las decisiones sean lentas, porque se espera el voto de conformidad de todos sus integrantes, hasta el momento los Estados no se han puesto de acuerdo para adoptar un sistema por mayorías. Con la ampliación del MERCOSUR, mediante la incorporación de Venezuela y la próxima incorporación de Bolivia, veremos si se altera el modo de toma de decisiones.

6. Equidad o superación de asimetrías: se ha comenzado a incorporar el criterio de la equidad entre los Estados, salvando los obstáculos ineludibles generados por las inmensas asimetrías entre los Estados que conforman el MERCOSUR. Así se observan, en lo últimos órganos creados, diferencias en cuanto a la participación en el presupuesto, la creación del FOCEM, y normas más flexibles en la incorporación de normativa comercial en los países en condiciones menos favorables.

Como observamos, en el MERCOSUR existen principios de organización administrativa, que tienen origen en el derecho administrativo, pero también prin- 
cipios que rigen la estructura institucional propia del MERCOSUR con algunas particularidades. La estructura institucional del MERCOSUR está compuesta de órganos con asignación de competencias y responde, según el derecho administrativo, a una técnica de distribución de competencias propia de un modelo concentrado. Presenta en ciertos órganos decisorios una estructura de órganos colegiados intergubernamentales ( $\mathrm{CMC}, \mathrm{GMC}, \mathrm{CCM}$, etc.), en otros órganos características burocráticas de índole jerárquica (ST, SM, ISM, IPPDH, etc.), y en menor medida órganos con atisbos de autarquía (TPR). La organización institucional del MERCOSUR, como vimos, presenta también una administración activa, interna, externa y una actividad discrecional y reglada.

Sin embargo, son principios propios de los órganos del MERCOSUR, ya que no surgen del derecho administrativo de los Estados, los siguientes: a) Equilibrio: cada institución es dirigida por una autoridad cuya designación rota siguiendo el orden alfabético, del mismo modo que rotan las Presidencias Pro Tempore (РPT), y el equilibrio de nacionalidades en las personas físicas; b) Consenso: debe estarse en pie de igualdad y decidirse con un voto cada uno; c) Equidad o superación de asimetrías: ha de existir equidad entre los Estados, por ejemplo en la participación en el presupuesto, y mayor flexibilidad para la incorporación de normativa comercial en los países en condiciones menos favorables.

\section{CONSIDERACIONES FINALES}

Las diferencias entre la estructura organizacional de los Estados-nación y la de los procesos regionales ponen de presente la necesidad de implementar principios especiales para los órganos del MERCOSUR. La adopción de principios propios es necesaria siempre que se consideren las características actuales de los órganos para los fines de consolidar la integración regional ${ }^{57}$. La característica más trascendental de las estructuras organizativas del MERCOSUR en la actualidad consiste en el carácter intergubernamental.

En relación a esa particularidad se vislumbra en la estructura actual una gran concentración de funciones en los órganos con capacidad decisoria. La cantidad de órganos auxiliares subordinados a la tutela de los mismos implica una concentración de funciones y decisiones que tornan más lento el proceso de integración. No obstante, los cambios relacionados con la ampliación de la agenda del proceso regional son muy positivos respecto de la construcción

57 A pesar de que también son necesarias otras normas administrativas como teniendo en cuenta la necesidad de crear una normativa de procedimiento administrativo eficaz, normas de empleo público regional que garantice los derechos laborales de los funcionarios, la participación en las reuniones de toma de decisión, órganos de control externo regional, son algunos de los puntos a mejorar. 
de una identidad cultural en el MERCOSUR, así como también la intención de mejorar la participación ciudadana y la transparencia de las instituciones ${ }^{58}$.

La principal distinción que encontramos en las estructuras organizacionales y en los principios de administración pública a contemplar difieren especialmente en el modo de concebir la división de poderes: mientras en los Estados la misma resulta tajante, en los órganos regionales del MERCOSUR se presenta en modo más flexible (ya que existen órganos que poseen funciones ejecutivas, legislativas ${ }^{59} \mathrm{y}$ jurisdiccionales $)^{60}$. Estas diferencias han sido las que han desarrollado nuevos principios de organización adaptados a la realidad de los órganos del MERCOSUR.

Para concluir diremos que son varios los principios y elementos que la estructura institucional del MERCOSUR aplica en su funcionamiento que responden a los principios de organización administrativa del derecho administrativo, y que surgen inevitablemente por el solo hecho de existir una organización institucional con atribución de competencias delegadas por los Estados. La identificación de estos principios es útil para pensar el esquema propuesto por el MERCOSUR, y esperamos que den lugar a futuras e interesantes reflexiones. No obstatne, sería un error pretender trasladar los principios que rigen las organizaciones administrativas internas de los Estados Parte, en forma supletoria, sin considerar la naturaleza de estas instituciones regionales. La adaptación de principios debe darse por analogía, respetando las particularidades del derecho de la integración. Asimismo, se ha evidenciado el desarrollo de principios propios de la organización regional acordes a los fines para los que fue creada. Sin embargo, notamos la ausencia de una norma de organización más amplia, que posibilite la aplicación de una norma de procedimientos administrativos, y la posibilidad de acción recursiva. Una buena organización administrativa que tienda a profundizar el proceso de integración (que es el fin mismo de esa estructura institucional) ahorrará recursos y capacidades para el beneficio de todos los que pertenecen a un proceso de integración que alcanza a los doscientos noventa y cinco millones de habitantes.

\section{BIBLIOGRAFÍA}

Alessi, Renato (1978). Principi di diritto amministrativo, I. 4. ${ }^{\text {a }}$ ed. Milano. CMC/DEC n. ${ }^{\circ} 4 / 13$ de Derecho a solicitar información a los órganos del MERCOSUR.

59 En el sentido de capacidad de creación de normas, y no como atribución de un parlamento electo por el voto popular con capacidad de sancionar normas de aplicación directa.

60 Gordillo, Agustín. Siguiendo en el concepto de jurisdicción a GordiLlo en su división de tareas judiciales de aquellas jurisdiccionales realizadas por órganos de encuadre ejecutivo, 
Alessi, Renato (1949). Diritto Amministrativo. Milano: Giuffrè.

Balbín, Carlos F. (2008). Curso de Derecho Administrativo. Buenos Aires: La Ley.

BARREIRA, EnRIQUE (2008). Algunas dificultades que presenta el Marco Jurídico del Mercosur, en Leita, Francisco y Negro SAndra (coords.), La Unión Europea y el Mercosur: a 50 años de la firma de los Tratados de Roma. Buenos Aires: La Ley.

Leita, Francisco, Negro Sandra (Coords.) (2008). La Unión Europea y el Mercosur: a 50 años de la firma de los Tratados de Roma. Buenos Aires.

Caetano, Gerardo (2006). Parlamento Regional y Sociedad Civil en el Proceso de Integración. Una nueva oportunidad para -otro-MERCOSUR? Montevideo: Análisis y Propuestas, Friedrich Ebert Stiftung.

Cajarville Peluffo, Juan Pablo (1998). Garantías constitucionales del procedimiento administrativo en los países del MERCosur. Principios del procedimiento administrativo de los órganos del MERCOSUR. Revista AeDP 4, septiembre-diciembre, pp. $26-47$.

Cassese, Sabino (1998). Derecho Administrativo Comunitario y Derechos administrativos nacionales. Revista AeDP 4, mayo-agosto, pp. 31-56.

Cassese, SABino (1999). Ordenamientos internacionales, organizaciones supranacionales. Revista AeDP 5, enero-abril, pp. 15-23.

CZAR DE ZALDUENDO, SusAna (2003). La institucionalización en los acuerdos regionales: el caso del Mercosur, en BASEvi, Giorgio, Donato, Vicente y O'Connell, ARTURO (comps.), Efectos reales de la integración regional en la Unión Europea y el Mercosur. Buenos Aires: Universidad de Bolonia.

DURÁN MARTínEZ, RUBÉN (1999). MERCOSUR y organizaciones administrativas nacionales. Revista AeDP 5, enero-abril.

GAJATE, Rita (ed. y dir.) (2014). Construcción Institucional en el MERCOSUR. UNLP.

García Trevijano Fos (1967). Tratado de Derecho Administrativo, t. II. Madrid: Revista de Derecho Privado.

Giannini, Massimo Severo (1991). Derecho Administrativo, vol. I, trad. Luis Ortega. Madrid: Ministerio para las Administraciones Públicas.

GonzÁlez Moras, JuAn M. (2004). Principios de Organización Administrativa en las Instituciones del Mercosur. Texto de las "Jornadas sobre organización administrativa, función pública y dominio público", organizadas por la Universidad Austral, Buenos Aires, 21 de mayo de 2004. 
Principios de organización administrativa en la estructura institucional del MERCOSUR 233

Gordillo, Agustín (2013). Tratado de Derecho Administrativo y Obras Selectas, t. I, Capítulo VI, XIV. Buenos Aires: FDA.

LeITA, Francisco y Negro SANDRA (Coords.) (2008). La Unión Europea y el Mercosur: a 50 años de la firma de los Tratados de Roma, Buenos Aires: La Ley.

Marienhoff, Miguel S. (1965-1993). Tratado de Derecho Administrativo. Buenos Aires: Abeledo Perrot.

Mata, Ismael (2009). Ensayos de Derecho Administrativo. Buenos Aires: Ediciones RAP.

MÉNY, YVES (1999). El impacto de la integración sobre los sistemas administrativos y políticos; la experiencia europea. Revista AeDP 5, enero-abril, pp. 25-50.

Ruiz DíAz LABRANO, Roberto (1995). Supranacionalidad e integración, en La integración bacia el siglo XXI. V Encuentro Internacional de Derecho de América del Sur. Montevideo.

SALOMONI, JorGe (1998). Procedimiento administrativo y MERCOSUR. Una aproximación a los principios emergentes de los distintos ordenamientos aplicables. Revista AeDP 4, septiembre-diciembre, pp. 95-130.

Santamaría Pastor, Juan Alfonso (1984). La Teoría del Órgano en el Derecho Administrativo. Revista Española de Derecho Administrativo n. ${ }^{\circ}$ 40/41, enero-marzo.

ScotTi, Luciana (2010). El Derecho de la Integración en el Mercosur, en SANDRA Negro (dir.), Derecho de la Integración. Manual. Buenos Aires: B de F.

Suñé, NATAsha (2014). Posibles cambios en el Sistema de Solución de Controversias del mercosur, en Rita Gajate (ed. y dir.), Construcción institucional en el merCosur. UNLP, pp. 131-133. 